\title{
Leveraging water infrastructure for transformative socio-economic development in South Africa
}

\author{
O. Busari \& J. Ndlovu \\ Trans-Caledon Tunnel Authority, Centurion, South Africa
}

\begin{abstract}
Building economic and social infrastructure is at the heart of the national developmental agenda in South Africa, and plans include those for enhancing the capacity of existing water resource infrastructure to meet competing needs across all sectors. Indeed, water is arguably the most pivotal natural resource for meeting the socio-economic needs of South Africa as a developmental state. It is understandable, therefore, that there is increasing expectation to provide water to support all the development objectives of the state, including poverty alleviation and rural development. In the light of the challenge to drive down unemployment levels, including among the youth as amplified in the New Growth Path underpinning the country's economic development, the rollout of mega-projects such as those for large water infrastructure is required to be innovatively structured to create more jobs and have a real positive impact on the lives of the poor. This paper evaluates the expanding operational model of the TransCaledon Tunnel Authority, a state-owned entity, beyond its primary mandate to finance and implement bulk water infrastructure projects without recourse to the fiscus, into strategically mapping out all project interventions to facilitate social transformation and build sustainable communities. This developmental priority is demonstrated by the manner in which water infrastructure projects are now implemented by the organization and its collaborators. Key elements include the development of economically sustainable funding models; innovative management of debt within a prudent risk framework; and, most importantly, implementation of cost-effective and environmentally sound infrastructure emphasizing socio-economic strategies for transforming project communities and building small, medium and micro enterprises.
\end{abstract}

Keywords: water infrastructure, social transformation, sustainable project communities, TCTA, South Africa. 


\section{Introduction}

South Africans view the notion of water for development as emphasizing the role of water in alleviating poverty and the rights of communities to have access to safe drinking water. While significant progress has been made in reducing historical backlogs in community water supply, there remain concerns about lack of access to reliable services in some parts of the country, leading to increased vulnerability to water-related diseases. Government continues to underscore its commitment to the pursuit of universal access to water and sanitation by 2014, both by investing in new infrastructure and by maintaining and rehabilitating dysfunctional systems to minimize water losses and service deterioration and disruption. Closely related to this priority is the need to increasingly build municipal capacity to sustain the infrastructure underpinning efficient service delivery to communities, while improving equitable access.

Equity and sustainability of water management are at the heart of the Water for Growth and Development Framework, adopted in 2009 (Republic of South Africa [1]). There is recognition that the country is water-scarce and that it faces many challenges as a result of the limited and variable nature of its water resources, including the impacts of climate change. The framework presents a response to those challenges, and guides actions and decisions among key sector role-players to ensure that water continues to drive economic growth and social development.

Ahead of several other countries across the world, developing as well as developed, South Africa is emerging from a global recession into new periods of economic performance, recording a GDP growth of $2.7 \%$ in 2010 , with growth forecasts for 2011 ranging from 3.0 to $3.4 \%$. The global financial crisis sustained an environment of low economic growth and low inflation, driving the lowering of short-term interest rates to levels unseen in South Africa in the past 35 years. The crisis also brought about disparities in growth rates and financial asset class performance between developed and emerging markets, allowing foreign capital inflows to drive domestic yields to current levels. Going forward, the recovering growth is expected to be recorded side-by-side with rising inflation, and it is noteworthy that the market is already pricing in a gradual rise in interest rates from 2012, with implications for infrastructure funding strategies.

There are intensified efforts to identify opportunities for broader areas of growth and economic participation, to progressively set the country on a new trajectory of growth and development. Expanding economic and social infrastructure continues to be a national priority, including the critical infrastructure for augmenting water resources to meet strategic needs in the electricity sector (e.g. for Eskom) and the industrial sector (e.g. for Sasol), as well as for mining and domestic requirements. Such strategic water infrastructure plans are at the core of government's infrastructure programme over the short to medium term, underlining the urgency of those interventions.

In terms of South Africa's New Growth Path which drives the country's economic development (Republic of South Africa [2]), state-owned entities involved in large infrastructure projects are required to ensure the pro-poor 
expansion of infrastructure, visibly creating employment and promoting broadbased economic growth. Indeed, in the developmental state envisioned by the South African government, state-owned entities are expected to direct their resources to achieve national development goals (Republic of South Africa [3, 4]). The expectation to facilitate the integration of infrastructure development into wider socio-economic development is consistent with the synergistic results achieved by East Asian states with their huge investments in infrastructure following the recent global financial crisis, Abidin [5], and much earlier in postWorld War II Japan (Yoshida [6]).

This paper points to the positioning of the Trans-Caledon Tunnel Authority (TCTA), a state-owned liability management organization mandated to finance and develop bulk raw water resource infrastructure, to chart a more influential project path in transformative socio-economic development. Following an articulation of corporate strategic direction and supporting operational principles underscoring best practice water project finance and management, the paper summarizes the approaches adopted for ensuring that water infrastructure projects serve as leverage for social transformation and community upliftment.

\section{Water infrastructure and the TCTA}

South Africa, with a highly variable rainfall, is one of the driest countries in the world. The problem of water scarcity is compounded by the geographic mismatch between its relative availability in certain catchments and the nodes of strategic industrial activities driving economic growth. Consequently, in order to assure a reliable supply of water to areas of greatest need, the country has developed an extensive system of storage and transfer schemes - collectively termed the National Water Resource Infrastructure - over the decades.

While the national water resource infrastructure system is planned and overseen by the Department of Water Affairs (DWA), in a manner that ensures integrated resource management and sustainable national supply, the TCTA was established specifically to finance and develop the bulk water infrastructure for which it has been determined that the user base is strong enough to generate the revenues required to offset loan financing of individual projects.

The Trans-Caledon Tunnel Authority came into being in 1986 as a result of a Treaty signed between South Africa and Lesotho on the implementation of the Lesotho Highlands Water Project (LHWP). The TCTA was formally established in terms of a Government Notice in 1986, and water delivery from LHWP commenced in 1998, with the final completion of that phase in 2000. In terms of the Treaty, TCTA was responsible for implementing, operating and maintaining that part of the LHWP located within South Africa, as well as any other function the Minister so directed. As a result thereof and having due regard to TCTA's performance on the LHWP, the notice of establishment was amended in 2000, to enable TCTA to fulfill all of South Africa's financial obligations on the project, including liability management, and to allow the Minister to issue directives to TCTA with regard to other projects. Since then, TCTA has performed a number 
of functions across the realms of project finance and implementation on behalf of government, for specifically directed projects.

Today, therefore, TCTA is mandated to finance, develop and implement bulk raw water infrastructure within an acceptable risk framework and in the most cost-effective manner to benefit water users. In executing its mandate from project to project, the TCTA operationalizes the business model shown in the schematic in figure 1, allocating risks to parties best suited to managing them, and setting tariffs to ensure project affordability by water users and debt repayment within a reasonable period. In relation to liability management, the focus and activities of TCTA cover the entire project cycle: from raising finance for the project to overseeing engineering, construction and the environmental components of project implementation. Using its expertise, the TCTA also plays an important role as an advisor in the water sector, on wide-ranging issues spanning project initiation, restructuring of treasury activities and the review of water tariff methodologies.

While the business model at TCTA has always been acknowledged as knowledge-rich, the knowledge processes have been predominantly implicit.

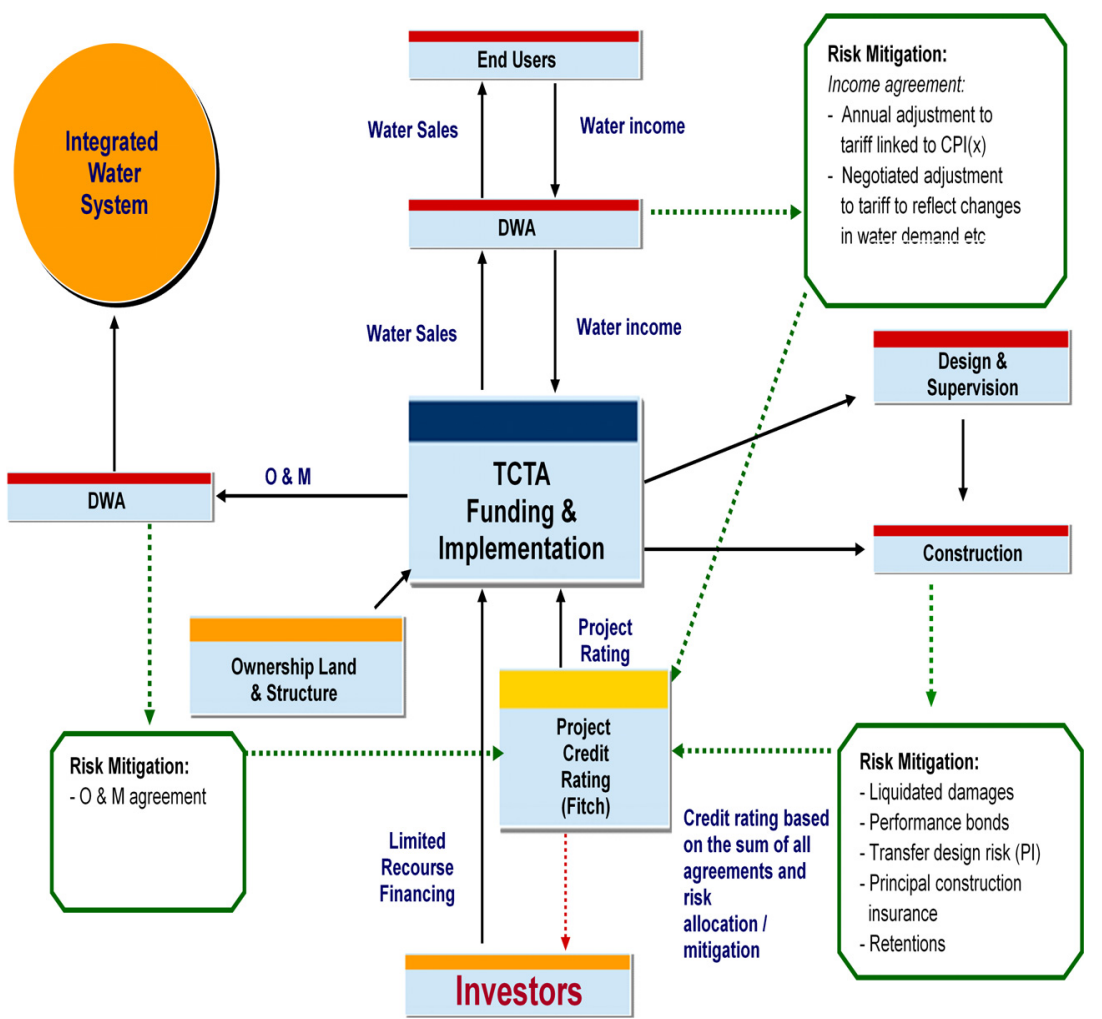

Figure 1: $\quad$ TCTA's business model. 
Recently, TCTA made a deliberate move to position itself as a knowledge institution, so as to increasingly leverage the strategic value of knowledge management for the benefit of the organization and its partners and stakeholders. At the heart of the knowledge agenda (Busari [7]), is the deployment of specialist skills and smart partnerships as a differentiating factor for innovating solutions to development challenges, while fostering a corporate environment that values learning and knowledge sharing, and reinforcing supportive mechanisms for knowledge integration across the entire organization.

Several institutions are active in the water value-chain in South Africa, figure 2, and the National Water Act of 1998 is explicit on sector institutional relationships based on statutory authority. In the family of sector institutions, TCTA has progressively become the de facto agency for funding and implementing water resource infrastructure projects on an off-budget basis. Each project requires the development of an implementation agreement between TCTA and DWA, outlining specific requirements and conditions as depicted in figure 3 .

\section{Strategic direction and competencies}

The TCTA recently developed a strategic perspective of its future, characterized as The Brave New World, describing the organization's strategic intent and ambitions. This repositioning initiative includes the reconfiguration of its current

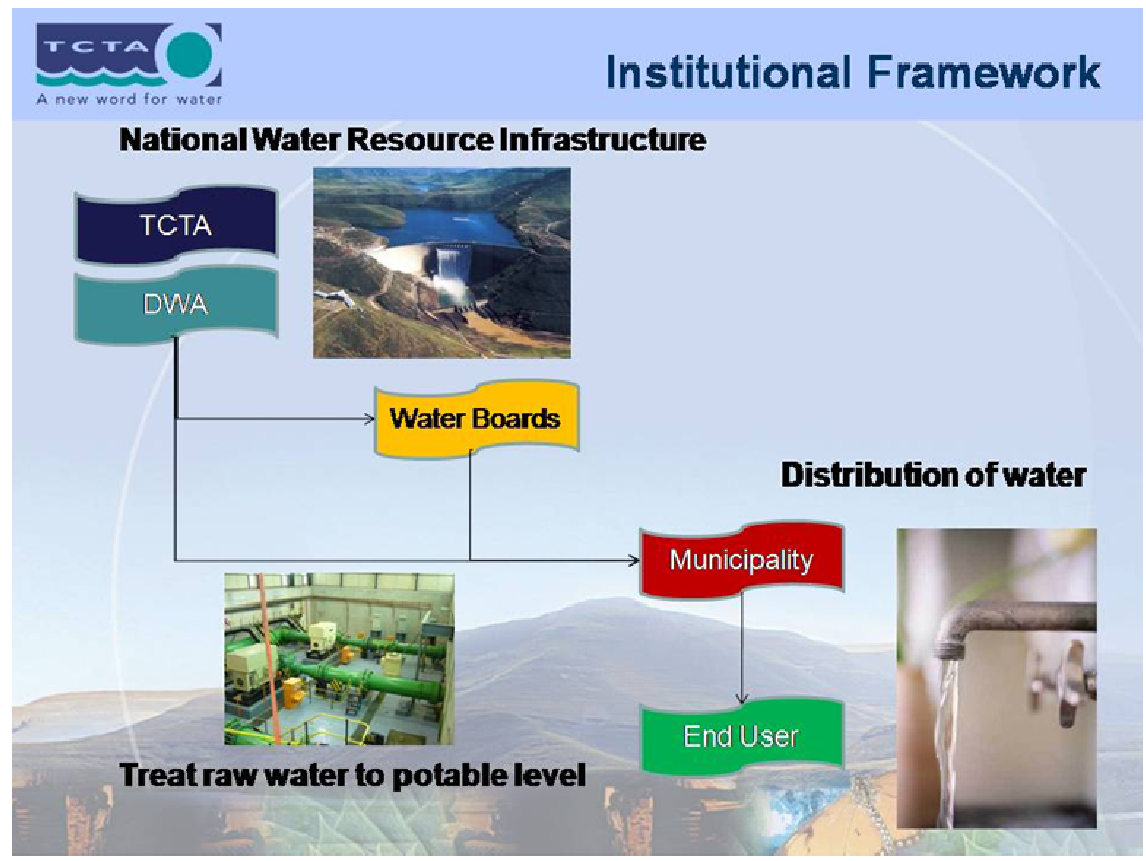

Figure 2: Water sector institutional relationships. 


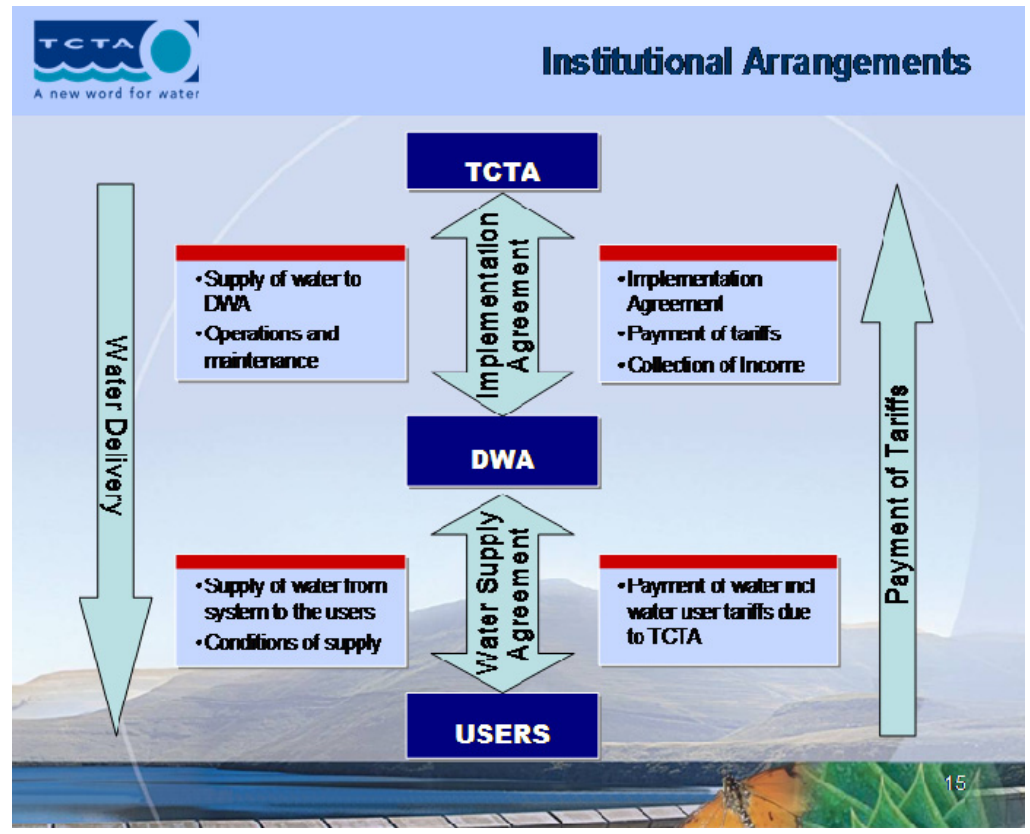

Figure 3: $\quad$ Project institutional arrangements between TCTA and DWA.

business model to allow for the pursuit of expanded project opportunities and enhanced thought leadership for policy reform and advocacy, as well as for supporting water utilities and other state institutions in developing infrastructure in critical areas of need.

Going forward, the new corporate strategy provides the frame of reference against which TCTA will develop the resources and value propositions to its future clients and stakeholders. This frame enables the organization to increasingly leverage its technical skills and experiences in planning and implementing complex infrastructure projects and managing liability over several years, positioning itself as a preferred provider of innovative solutions to water sector and broader development challenges.

TCTA's corporate goals are aligned with the strategic imperatives of government, in the context of its mandate and expected deliverables. The strategic goals are as follows:

- Deliver on all the directives provided by the Minister relating to the planning, implementation and financing of bulk raw water infrastructure, in accordance with specifications and within agreed timelines and budget.

- Ensure that all project activities facilitate social transformation and build sustainable communities by providing jobs and empowering women and youth and the disabled. 
- Operate the business and its projects and processes in a cost-effective manner, bearing in mind the imperatives of public finance management.

- Build the knowledge and capability of the organization to support other institutions, in pursuit of greater efficiencies in overall water management and water services delivery.

- Ensure the continuous availability of high-calibre human capital for delivering on the organizational mission into the future.

The competencies of TCTA reflect its growth and experiences from the days it operated in a single project environment, following establishment as a special purpose vehicle in 1986. In line with government policy and practice to seek offbalance-sheet commercial funding options for infrastructure projects that are economically and commercially viable, subsequent legislative amendments have resulted in TCTA becoming the de facto national agency in respect of bulk raw water resources infrastructure. The scope of TCTA's activities has expanded considerably in scale and complexity, from a single project to the management of the current portfolio of eight major infrastructure projects at varying stages in the project life-cycle.

Consequently, TCTA has developed sound expertise and an acknowledged track-record in the efficient financing and project management of water infrastructure delivery, as diagrammatically shown in the business process architecture in figure 4 . The competency set renders it well-placed to assume increased responsibilities and functions within an enhanced business framework.

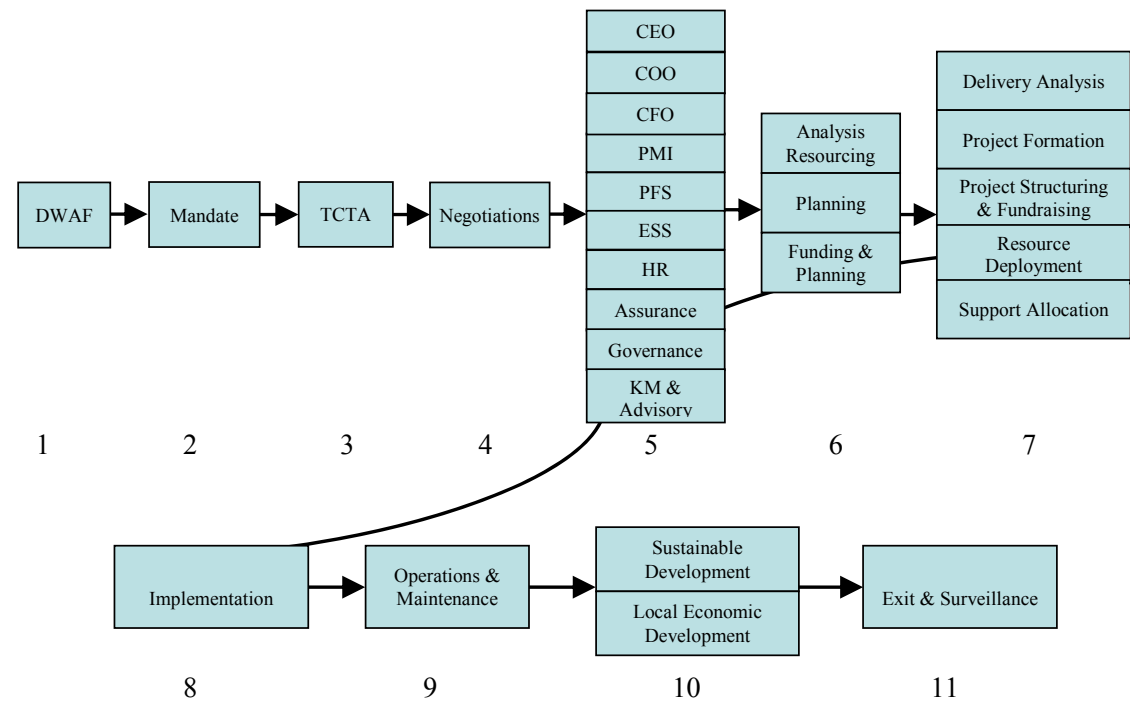

Figure 4: TCTA's business process architecture. 


\section{Operating principles}

The following key principles, TCTA [8], underpin TCTA's current business model:

- Operating in a multi-project ring-fenced environment

- Maintaining constant tariff in real terms

- Adopting a risk-averse philosophy

- Implementing best practice in project management approaches

- Establishing best practice in environmental sustainability

\subsection{Multi-project ring-fenced environment}

Each TCTA project is ring-fenced, accounted for and managed separately, including in terms of their funding and income streams. Based on the specifics of each roject, the risk is packaged and allocated to parties best suited to managing them. The TCTA funds and implements projects for which back-to-back impplementation agreements have been concluded between TCTA and DWA, simultaneously with water supply agreements between DWA and off-takers. This approach secures the income streams from off-takers with an implied guarantee on the income streams from DWA. This business approach has been acknowledged as a successful model for public-public and public-private partnerships.

\subsection{Constant tariff in real terms}

TCTA annually sets a constant tariff in real terms to end-users of water from each of its projects, over the period of repayment of the debt, based on agreed input assumptions. Such assumptions include the prevailing level of inflation, and income agreements usually allow for automatic and negotiated adjustments.

The approach is to charge actual costs, such that lower costs lead to lower tariff. Also, since TCTA operates on a non-profit basis, any savings are transferred to the benefit of water users. This smoothed tariff methodology, approved by government, may result in interest being capitalized on a project, thus showing a deficit situation even after construction is complete. However, whether or not this happens is dependent on the agreement with water off-takers.

\subsection{Risk-averse philosophy}

In managing risks, TCTA adopts a low level of risk tolerance. This philosophy is embedded in the organization's strategic framework and policies, resulting in the minimization of both financial and non-financial risks.

The operating principle takes the following into account: the specific risks associated with project implementation such as construction, environmental and geotechnical; the financial risks associated with the management of liability; and 
the ability of the risk management processes to reinforce the business objectives of the organization.

\subsection{Best practice in project management approaches}

TCTA developed a Project Implementation Methodology (PIM) based on the principles of the Project Management Body of Knowledge. The PIM provides detailed processess and procedures on all project implementation activities, covering the full project lifecycle from initial planning to project commissioning and handover.

The PIM ensures standardization of project implementation processes across all projects within TCTA's multi-project environment. Further system developments are undertaken to support and enhance the PIM, notably the use of Primavera for contract management, scheduling, cost management and document control. As part of the TCTA inititiative on Total Quality Management, ISO compliance for the PIM is an ongoing objective.

\subsection{Best practice in environmental sustainability}

The environmental sustainability framework at TCTA incorporates information systems that enable the integration of sustainability into business planning; enhancement of the positive impacts of project implementation; and internalization of negative project impacts as part of project controls, so that they don't become social costs.

The environmental management plan for each project provides the frame and scope for socio-economic strategies, environmental design guidelines, contractual specifications and monitoring of environmental impacts on the project area, to ensure compliance with the record of decision.

\section{Broad economic and environmental performance}

Economic performance at TCTA is indexed by organizational ability to deliver on the requirements of individual projects in the most cost-effective manner, within agreed timelines and budgets. This TCTA commitment is met through: developing economically sustainable funding models; implementing costeffective and environmentally sound infrastructure, including environmental management and socio-economic strategies for transforming project communities; and managing debt more innovatively within a prudent risk framework.

Because of the scale of the capital investments, each running into billions of rands (US\$1=R7), TCTA's infrastructure interventions are driven by clear indicators of the requirement, and the explicit willingness, of water users to pay the costs of development. In such circumstances, the financial market, together with agreements on future water requirements, is accepted as an appropriate mechanism for funding infrastructure for economic purposes. However, challenges remain with building understanding and acceptance of the imperative that the price of water needs to reflect the investment and scarcity value. 
Fortunately, there are ongoing consultations to develop a new national water pricing strategy that takes cognizance of the full costs of managing water resources and supplying water to users, anchored on a funding model that would be benchmarked against best practice globally.

As alluded to previously, environmental performance relating to interventions on environmental management and social sustainability is guided by strategies seeking to integrate sustainability into both business and project planning, and to promote a culture of sustainability at corporate and project implementation levels. Organizational approach to ensuring sound environmental performance, TCTA [9], underscores objectives-based planning, implementation, monitoring and evaluation. In practice, therefore, drawing on the framework of the International Environmental Management System, the approach emphasizes monitoring and review feedback mechanisms.

\section{Facilitating socio-economic transformation}

The organization's strategy for transformative socio-economic development in projects seeks to achieve the following objectives:

- Providing developmental business access for small, micro and medium enterprises in the context of infrastructure project implementation.

- Facilitating employment opportunities and undertaking skills development to improve entrepreneurial ability and socio-economic empowerment.

- Promoting and developing agribusiness and other agricultural activities through focused technical and managerial support, in the course of implementing Sustainable Utilization Plans around project dams.

- Partnering with public health institutions to share knowledge addressing chronic diseases, including HIV and tuberculosis, leading to healthier project communities.

Through a careful planning and execution of each step within the cycle of its multiple projects, the TCTA has positioned itself to play a more decisive role in the evolution of the country's social and economic development. Each project is now structured in such a way as to provide livelihood and job opportunities, as well as mentoring and skills transfer to project communities, contributing to sustainable socio-economic growth and poverty alleviation. In executing its mandate from project to project, TCTA actualizes its strong belief in local empowerment, hence the appointment of local labour and skills for each project, ensuring knowledge application and acquisition, labour utilization and wealth creation.

In particular, while TCTA encourages people to be entrepreneurial, it is increasingly also instilling the urge to transform the entrepreneurial thinking into practical application, thereby coverting entrepreneurship into visible projects. Central to enterprise development is a newly adopted innovative policy: large engineering organizations involved in infrastructure construction works are now 
required to take under their wing, smaller emerging companies, systematically transferring skills and providing mentorship.

To facilitate the smooth implementation of the foregoing strategy, TCTA has established a Socio-economic Development Fund in the Office of the Chief Executive Officer. Robust monitoring and evaluation of all transformation targets are planned, to ensure continuing value creation for project stakeholders across social, economic and environmental dimensions.

\section{Conclusions}

The development of national water resource infrastructure for predominantly economic purposes has provided the Trans-Caledon Tunnel Authority a vital opportunity to make water available for social needs, through schemes that may otherwise be unaffordable for local communities. But it has also provided the springboard for playing a key role in the broader initiative of government to transform the socio-economic landscape of South Africa. The transformative initiatives at TCTA support the national agenda for development by positioning the organization as a catalyst for change in project communities, as well as facilitating the development of small, medium and micro enterprises in the rollout of mega infrastructure projects.

In the context of the continuing project directives from government, TCTA is viewed as a preferred borrower in the national and global capital markets even at the height of a gloomy sentiment in the markets in the past year, in the face of a global credit crisis manifesting in dwindling liquidity, widening credit spreads, worsening inflation expectations and rising interest rates. Over the past two decades, TCTA is acknowledged as meeting and, indeed, exceeding its mandate to plan, finance and implement bulk raw water infrastructure, successfully leveraging knowledge and innovation to catalyze infrastructure development. Such experience prepares the TCTA for a pivotal organizational role into the future, equipping it to further deepen its socio-economic contributions to the wider South African society.

\section{References}

[1] Republic of South Africa, Water for Growth and Development Framework, Department of Water Affairs, Pretoria, 2009.

[2] Republic of South Africa, The New Growth Path, Department of Economic Development, Pretoria, 2010.

[3] Republic of South Africa, State of the Public Service Report, Office of the Public Service Commission, Pretoria, 2007.

[4] Republic of South Africa, Definition of the Developmental State, Presidential Review Commission on State-Owned Entities, Pretoria, 2011.

[5] Abidin, M.Z., Fiscal Policy Coordination in Asia: East Asian Infrastructure Investment Fund, Working Paper Series no. 232, Asian Development Bank Institute, 2010. 
446 Environmental Impact

[6] Yoshida, T., Japan's experience in infrastructure development and development cooperation. JIBC Review, 3, pp. 62-92, 2000.

[7] Busari, O., Designing the future: the knowledge agenda at Trans-Caledon Tunnel Authority. International Journal of Knowledge, Culture and Change Management, 10(3), pp. 145-158, 2010.

[8] TCTA, Corporate Plan 2011/12, Trans-Caledon Tunnel Authority, Centurion, 2011.

[9] TCTA, Annual Report 2010/11, Trans-Caledon Tunnel Authority, Centurion, 2011. 